Fixed Point Theory, 22(2021), No. 1, 315-326

DOI: $10.24193 /$ fpt-ro.2021.1.22

http://www.math.ubbcluj.ro/ nodeacj/sfptcj.html

\title{
ON THE SU-YAO THEOREM
}

\author{
LECH PASICKI
}

AGH University of Science and Technology, Faculty of Applied Mathematics, Al. Mickiewicza 30, 30-059 Kraków, Poland

E-mail: pasicki@agh.edu.pl

Abstract. Su and Yao [Fixed Point Theory Appl. 2015:120 (2015)] have proved a fixed point theorem for mappings in metric spaces satisfying a general contraction condition. In their paper numerous examples of important consequences of this theorem are given. Our main aim is to present an extension of the Su-Yao theorem to the case of dislocated metric spaces. The proof is short, the result is stronger also for metric spaces, and the theorem itself is a natural and elegant extension of the celebrated Banach fixed point theorem.

Key Words and Phrases: Dislocated metric, partial metric, fixed point, general contraction 2020 Mathematics Subject Classification: 54H25, 47H10.

Acknowledgements. This work was partially supported by the Faculty of Applied Mathematics AGH UST statutory tasks within subsidy of the Polish Ministry of Science and Higher Education, grant no. 11.11.420.004.

\section{REFERENCES}

[1] H. Aydi, W. Shantawi, M. Postolache, Z. Mustafa, N. Tahat, Theorems for Boyd-Wong-type contractions in ordered metric spaces, Abstr. Appl. Anal., 2012, ID 359054.

[2] D.W. Boyd, J.S.W. Wong, On nonlinear contractions, Proc. Amer. Math. Soc., 20(1969), 458464.

[3] P. Hitzler, A.K. Seda, Dislocated topologies, J. Electr. Engin., 51(12)(2000), 3-7.

[4] G.F. Jungck, B.E. Rhoades, General fixed point results in dislocated metric spaces, Fixed Point Theory, 18(2)(2017), 615-624.

[5] W.A. Kirk, P.S. Srinivasan, P. Veeramani, Fixed points for mappings satisfying cyclical contractive conditions, Fixed Point Theory 4(1)(2003), 79-89.

[6] S.G. Matthews, Partial metric topology, Proc. 8th Summer Conference on General Topology and Applications, Ann. New York Acad. Sci., 728(1994), 183-197.

[7] S. Oltra, O. Valero, Banach's fixed point theorem for partial metric spaces, Rend. Istit. Mat. Univ. Trieste, 36(2004), 17-26.

[8] L. Pasicki, Fixed point theorems for contracting mappings in partial metric spaces, Fixed Point Theory Appl., 2014:185(2014).

[9] L. Pasicki, Dislocated metric and fixed point theorems, Fixed Point Theory Appl., 2015:82(2015).

[10] L. Pasicki, The Boyd-Wong idea extended, Fixed Point Theory Appl., 2016:63(2016).

[11] L. Pasicki, Some extensions of the Meir-Keeler theorem, Fixed Point Theory Appl., 2017:1(2017). 
[12] L. Pasicki, Dislocated quasi-metric and generalized contractions, Fixed Point Theory, 19(2018), no. $1,359-368$.

[13] S. Romaguera, A Kirk type characterization of completeness for partial metric spaces, Fixed Point Theory Appl., art. ID 493298 (2010).

[14] I.A. Rus, Cyclic representation and fixed points, Ann. Tiberiu Popoviciu Semin. Funct. Eq. Approx. Convexity, 3(2005), 171-178.

[15] W. Shantawi, M. Postolache, Coincidence and fixed point results for generalized weak contractions in the sense of Berinde on partial metric spaces, Fixed Point Theory Appl., 2013:54 (2013).

[16] Y. Su, J.C. Yao, Further generalized contraction mapping principle and best proximity theorem in metric spaces, Fixed Point Theory Appl., 2015:120(2015).

[17] F.M. Zeyada, G.H. Hassan, M.A. Ahmed, A generalization of a fixed point theorem due to Hitzler and Seda in dislocated quasi-metric spaces, Arab. J. Sci. Eng. Sect. A, 31(2006), no. 1, 111-114.

Received: November 7, 2018; Accepted: December 16, 2019. 
